\title{
Breast Disease Pattern In Jos North Central Nigeria: A Review Of Mammography Reports.
}

\author{
Gabkwet AE (MBBS, FWACS), Gwom PM (MBBS, MSc, FWACS), Igoh EO (MBBS, FWACS), Taiwo YF \\ (MBBS, FWACS), Salaam AJ (MBBS, FMCR), Danjem SM (MBBS, FMCR)
}

\author{
* Department of Radiology, Jos University Teaching Hospital, Nigeria. \\ DOI: 10.29322/IJSRP.10.03.2020.p9909 \\ http://dx.doi.org/10.29322/IJSRP.10.03.2020.p9909
}

\begin{abstract}
Objectives: Mammography has remained the gold standard globally for breast cancer screening. Patients with breast lesions in our environment are generally anxious due to the fact that breast cancer is associated with high mortality. This study aims to review the pattern of breast lesions in our environment.

Method: This is a Retrospective study of Mammographic reports of women who had mammogram for screening and diagnostic purposes between March 2017 and November 2019.

Results: The commonest indication for mammography in the study was breast lump (38.6\%). BIRADS II was the most prevalent category constituting $40.3 \%$ followed by BIRADS I accounting for $27.3 \%$.Patients with Positive BIRADS (IV and V) for malignancy account for $19.1 \%$ while Negative BIRADS (I, II and III) accounted for 79.6\%.

Conclusion: Majority of the breast lesions were benign and breast lump was the most prevalent complaint.
\end{abstract}

Index Terms- Breast cancer, Mammography, BIRADS, Breast Lump

\section{INTRODUCTION}

$\mathrm{T}$ he American College of Radiology (ACR) developed Breast Imaging Reporting and Data System (BI-RADS), which was first published in 1993 and subsequently upgraded in 2003 to cover findings in Ultrasonography and Magnetic Resonance Imaging have so far achieved the goal of harmonizing and standardizing the system of reporting breast diseases. The BIRADS system of reporting uses specific terminology to describe lesions in the breast and which conclusions are derived and classified into groups ranging from 0 to $6^{1}$.

Guidelines for imaging a palpable breast lump differ for different age groups. However, mammography remains the mainstay for patients above age forty and ultrasonography for patients who are thirty and below. Current ACR guidelines for evaluation of women age 30-39 years with palpable breast masses still stipulates mammography in addition to ultrasonography ${ }^{2}$. This is as a result of its high sensitivity to depict subtle breast lesions $^{3}$. In Nigeria and most developing countries of the world, the increase availability of mammography and other imaging modalities has help in early detection of Breast cancer ${ }^{4,5}$.

Breast lumps are generally a cause of anxiety and worry to patients, their relations and the care givers, especially knowing that the outcomes of such conditions like cancer comes with high rates of mortality and morbidity ${ }^{5,6}$.

Breast lesions are generally grouped into benign or malignant breast lesions. The pattern of breast lesions on mammography differ worldwide with studies in sub-saharan Africa showing over $70 \%$ of breast lesions are benign with malignant lesions account for the balance. ${ }^{6,8}$

This study seek to evaluate the pattern of breast lesions as depicted by mammography in women presenting for routine screening and diagnostic purposes in Jos North Central Nigeria.

\section{MATERIALS AND METHODS}

This is a retrospective study conducted in a privately owned diagnostic center in Bukuru, Jos North Central Nigeria covering a period of two years (2017-2019). Mammography request forms were used to extract patient's data e.g. age, sex, clinical history/indications and provisional diagnosis. Information corresponding to mammographic reports and BIRADS classifications which were previously reviewed by two qualified radiologist were then recorded.

In this study BIRADS 1, 2 and 3 are classified as Negative result for cancer, BIRADS 4 and 5 are classified as Positive result for cancer while BIRADS 0 is classified as inconclusive result that required additional evaluation with other imaging modality $7,9,10,19$. The data collected was collated and analyzed using the IBM SPSS STATISTICS VERSION 22.0 and EXCEL OFFICE 2013 was used to plot the charts.

Statistical significance was tested using Chi-square distribution (for test of difference in proportions). A p-value less than or equal to 0.05 was considered statistically significance.

\section{RESULTS}

The mean age of participants in the study was $47.1 \pm 11.2$ years with age range of 30-83years. Participants aged $40-49$ years $(42.9 \%)$ dominated the study population. Only $2.3 \%$ were 80 years and above. (Table 1 ).

The commonest indication for mammography was breast lump which accounts for $38.6 \%$ followed by pain in the breast which accounts for $24 \%$.Others include Itching (1.0\%), Nipple discharge (6.2\%), Nipple retraction (3.2\%), Routine check $(23.7 \%)$ and Breast swelling (3.2\%) (Table 2). 
The study revealed BIRADS category 2 accounting for majority 124(40.3\%) followed by BIRADS 1 which accounts for 84(27.3\%). A total of 59(19.1\%) had positive BIRADS for cancer while the majority $245(79.6 \%)$ had negative BIRADS for cancer. Only 4(1.3\%) were inconclusive needing additional investigation. Mean BIRADS score was $3.3 \pm 1.3$ with minimum score as 0 and the maximum score as 5. (Table 3).

The age group with the most participant with positive BIRADS score for cancer is 50-59 (22) followed by 40-49(14) and the least is age groups 70-79 and 80 and above with (4) each.

The study showed a significant statistical relationship between BIRADS Score and Age distribution of breast disease. $($ Chi-square 37.614, P-value $=0.023)($ Table 4$)$.

\section{DISCUSSION}

Universally, mammography has remained the gold standard for breast cancer screening and diagnosis due to its ability to depict small tumors that are hitherto not clinically palpable ${ }^{9,11}$. Dense fibroglandular breast tissue and overlap of tissues which beforehand has remained a stumbling block in the evaluation of breast masses has been overcome by the introduction of Digital Breast Tomosynthesis (DBT) which allows for three dimensional images of the breast to be reviewed ${ }^{12}$.

The indications for mammography are fluid globally and our study showed these accession, where majority of the participants indicated breast lump as the reason for undertaken the test, followed by breast pain and routine breast cancer screening. This is in agreement with previous findings by researchers on presenting complaints for mammography ${ }^{4,5,9,15}$. Breast pain as a presenting complaint accounted for $56.3 \%$ of the participants in a similar study in south east Nigerian ${ }^{14}$ and the most common complaint in another study done by Ehsanbakhsh MD et al in Iran ${ }^{7}$. The anxiety and worry that comes with the feeling of a lump in the breast most have been the reason for the percentage of women who presented at the center. However, a similar study in the same city under taken by Ozoilo $\mathrm{KN}$ et al on breast cancer screening indicated breast pain as the most common reason why women present for mammography ${ }^{16}$. The participants in our study were for both diagnosis and screening mammography and possibly the reason for the difference.

The BIRADS category 2 and 1 accounts for $40.3 \%$ and $27.3 \%$ respectively for the mammographic reports reviewed. Similar findings were documented in studies done by Obajimi MO et al, Akande $\mathrm{HJ}$ et al and Akinola RA et al in southwest Nigeria and Brakohiapa EK $\mathrm{t}$ al in Ghana. Positive BIRADS for Malignancy (category $4 \& 5$ ) accounted for $19.1 \%$ while a majority $79.6 \%$ are negative for malignancy (category $1,2 \& 3$ ).Studies globally have shown that benign breast lesions account for majority of breast lesions $3,6,7,13,19$.

In 1993, an international collation of randomized trials of breast cancer screening from various studies showed no significant benefit in outcomes for women aged 40-49 who have been enrolled into a screening program between 5-7years.It however, showed that screening reduces breast cancer deaths by about one third in women aged 50-59years ${ }^{20}$.

The peak age for breast cancer in Asia and the Western nations differ considerably with a lower peak age range (45-50) recorded in Asia and higher range noted in the west ${ }^{21}$.Our findings revealed age group 50-59 years have the highest number of women with BIRADS categories 4 and 5. Mawahib Rizig et al in Khatoum found a higher percentage of breast cancer in age group 41-55. Although our study encompasses both diagnostic and screening mammography and possibly the reason for this findings when compared with other studies in other parts of Nigeria and other developing Sub-Saharan countries where higher incidence of breast cancer were a decade earlier ${ }^{14,17,22,23}$.

of breast lesions world-wide are non-cancerous in nature and our study showed that with over $79 \%$ of the mammograms reviewed fall within BIRADS categories 1-3 while $19.1 \%$ of the participants had positive result for malignancy, 3,19,20,26,27. Ehsanbakhsh et al showed $91.7 \%$ accounting for benign breast disease while $11.9 \%$ of participants (screening and diagnostics) had positive results for cancer. Obajimi MO et al in a screening mammographic study in the south west of Nigeria reported $1.7 \%$ of the participants within the BIRADS categories 4 and 5.The lower percentage is attributed to the screening for breast cancer as against ours that encompasses both screening and diagnostic.

The study showed a significant statistical relationship between BIRADS Score and Age distribution of breast disease.

According to the American Cancer Society all women are at risk for developing breast cancer and estimates that one woman in every eight will develop the disease during her life time. A majority of such women will not have previous family or exposure histories that would have placed them at higher risk.

Our finding showed majority of the breast lesions are benign and the age group 50-59 years accounting for the highest number of BIRADS category positive for cancer.

\section{CONCLUSION}

Breast lump and pain accounted for more than half of the reason for mammography in this study. The most prevalent BIRADS category was BIRADS II and majority of the findings were negative for cancer (BIRADS I, II and III). The need for regular awareness on breast cancer and screening among young women within the internationally recommended age should be encouraged.

\section{REFERENCES}

[1] 1. American Cancer Society. Breast Imaging Reporting and Data System (BIRADS).2013

[2] 2. Ann LB, Jordana P, Priscilla JS, Zachary FV et al. Clinical value of Mammography in the evaluation of Palpable Breast Lumps in women 30 years old and older. AJR 2017; 209: 935-942

[3] 3. Akande HJ, Olalekan IO, Bola BO. Radiological findings of Breast Cancer screening in a newly equipped Centre. International Journal of Medicine and Medical Sciences.2011; 3(9):294-298

[4] 4. Akinola RA, Akinola OI, Shittu LAJ, Balogun BO, Tayo AO. Appraisal of mammography in Nigerian Women in a new teaching Hospital. Scientific Research and Essay.2007; 2 (8):325-329

[5] 5. Onwuchekwa RC, Alazigha NS. Mammographic profile of women with symptomatic breast diseases I Port Harcourt, Rivers State Nigeria. Research Journal of Health Sciences.2017; 5 (4):188-193

[6] 6. Brakohiapa EK, Armah GE, Clegg-Lamptey JNA, Brakohiapa WO. Pattern of Breast Diseases in Accra; Review of Mammography reports. Ghana Medical Journal.2013; 47(3):101-106

[7] 7. Ehsanbakhsh AR, Toosi FS, Khorashadizadeh N. Different BIRADS Categories in Screening and Diagnostic Mammography. Iran Journal of Radiology.2009;6(3):119-123. 
[8] 8. Olabukola ATO, Campbell PC, Irurhe NK, Atalabi OM, Toyobo OO. Breast Cancer Screening in a Resource Poor Country: Ultrasound versus Mammography.Ghana Medical Journal2017;51(1):6-12

[9] 9. Eni UE, Ekwedigwe KC, Adeoye IS, Daniyan ABC, Isikhuemen ME. Audit of Mammography request in Abakaliki, South-East Nigeria.World Journal of Surgical Oncology.2017;15:56

[10] 10.Nascimento JHR, Silva VD, Maciel AC. Accuracy of Mammographic findings in breast cancer: Correlation between BIRADS classification and histological findings. Radiology Basil.2010;43(2):91-96.

[11] 11.Nandi RJ, Nandi AK, Rangayyan RM, Scutt D. Classification of breast masses in mammogram using genetic programming and feature selection. Medical Biological Eng Comput.2006;44(8)683-694.

[12] 12.Peppard HR, Nicholson BE, Rochman CM, Merchant JK, Mayo III RC, Harvey JA. Digital Breast Tomosynthesis in Diagnostic setting: Indications and clinical applications. Radiographics.2015;35:4

[13] 13. Obajimi MO, Adeiji-Sofoluwe AT, Oluwasola AO, Adedokun BO, Mosuro OA et al. Screening mammography in Ibadan: Our experience. Nigerian Journal of Basic and Clinical Sciences.2015;12(2):74-80.

[14] 14. Ebubedike UR, Umeh EC, Anyanwu SNC, Ukah CO, Ikegwuonu NC. Pattern of mammography findings among symptomatic females referred for diagnostic mammography at a tertiary center in South-East Nigeria. West African Journal of Radiology 2016; 23(1): 23-27

[15] 15. Biggs MJ, Ravichandran D. Mammography in symptomatic women attending a rapid diagnosis clinic. A prospective study. Ann R Coll Surg Engl 2006; 88: 306-308

[16] 16. Ozoilo KN, Misauno MA, Chukwuogo O, Ozoilo JU, Ojo EO, Yakubu AA. Breast cancer screening in a resource poor setting: A preliminary report. J Med Trop. 2014; 16: 14-18.

[17] 17. Obajimi MO, Adeniji-Sofoluwe ATS, Oluwasola AO, Adedokun BO, Soyemi TO, et al: Mammographic breast pattern in Women in Ibadan. Breast Disease 2011/2012, 33:9-15.

[18] 18. Berg W, Gutierrez L, Nessaiver M et al. Diagnostic accuracy of mammography, clinical examination, US and MRI in preoperative assessment of breast cancer. Radiology 2004; 233(3): 830 - 849 .

[19] 19. Julianna M.R.B.Mello, Fernando P.Bittelbrunn, Marcio A.B.C R el at. Breast Cancer Mammographic diagnosis performance in a public health institution.A retrospective cohort study. Insight Imaging 2017;8: 581-588

[20] 20. Fletcher SW, Black W, Harris R, Rimer BK, Shapiro S (1993). Report of the international workshop on screening for breast cancer. JNCI J Natl Cancer Inst., 85(20): 1644-1656.

[21] 21. Toi M, Suzuki T, Saji S, Horiguchi K, Aruga T, et 1. Early breast cancer. Int J Clin Oncol. 2006;11(2):108-19.
[22] 22. Anyanwu SN (2000). Breast cancer in Eastern Nigeria: a ten year review. West Afr. J. Med., 19(2): 120-125

[23] 23. Okobia MN, Osime U (2001). Clinicopathological study of carcinoma of the breast in Benin City. Afr. J. Reprod. Health. 5(2): 56-62.

[24] 24. Ihekwaba FN. Breast cancer in Nigerian women. Br J Surg 1992; 79: 7715

[25] 25. Mawahib R,Awadia G,Ragaa A.A, AlaM.A.E,Ahmed Abd Elrahim Comparative study between us and mammography in diagnosis of breast masses in correlate to histopathology.SJAMS 2018; 6(10):3900-3906.

[26] 26. Varas X, Leborgne F, Leborgne JH Nonpalpable, probably benign lesions: role of follow-up mammography. Radiology 1992; 184: 409-414.

[27] 27. Monticciolo DL, Caplan LS. The American College of Radiology's BIRADS 3 classification in a nationwide screening program: Current assessment and comparison with earlier use. Breast J. 2004;10: 106.

\section{AUTHORS}

First Author - Gabkwet AE (MBBS, FWACS), Department of Radiology, Jos University Teaching Hospital, Nigeria.,

*Corresponding author. Phone Number:

$+2348033494974,+2348181836045$

E-mail address: tonygabs@yahoo.com

Second Author - Gwom PM (MBBS, MSc, FWACS)

Department of Radiology Federal Medical Center Keffi, Nigeria., E-mail address: gwoms2@yahoo.com

Third Author - Igoh EO (MBBS, FWACS)

Department of Radiology, Jos University Teaching Hospital,

Nigeria, E-mail address: igohson@yahoo.com

Fourth Author - Taiwo YF (MBBS, FWACS)

Department of Radiology, Jos University Teaching Hospital, Nigeria.., E-mail address: yetuexj@yahoo.com

Fifth Author - Salaam AJ (MBBS, FMCR))

Department of Radiology, Jos University Teaching Hospital, Nigeria. E-mail address: adeku2s@gmail.com,

Sixth Author - Danjem SM (MBBS, FMCR)

Department of Radiology, Jos University Teaching Hospital, Nigeria. E-mail address: samueljiblick@gmail.com,

\section{TABLES AND FIGURE OF LEGENDS}

Table 1: Age distribution of participants

\begin{tabular}{llll}
\hline Age (Years) & F & $\%$ & Mean \pm Std. \\
\hline $30-39$ & 33 & 10.7 & $47.1 \pm 11.2$ \\
$40-49$ & 132 & 29.5 & \\
$50-59$ & 91 & 11.7 & \\
$60-69$ & 36 & 2.9 & \\
$70-79$ & 9 & 2.3 \\
$80+$ & 7 & 100.0 \\
Total & 308 &
\end{tabular}




\begin{tabular}{|lll|}
\hline 45.0 & & 42.9 \\
40.0 & & \\
35.0 & & \\
30.0 & & \\
25.0 & & \\
20.0 & & \\
15.0 & 10.7 & \\
10.0 & & \\
5.0 & & \\
0.0 & $30-39$ & $40-49$ \\
& & \\
\hline
\end{tabular}

42.9

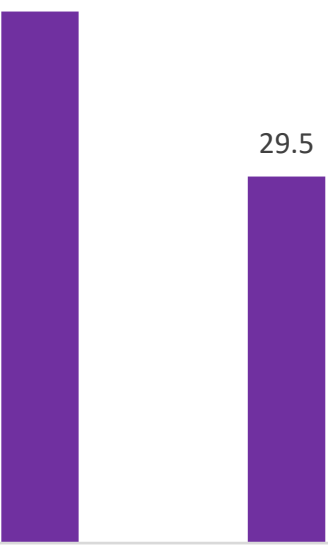

$50-59$
11.7

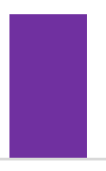

2.9

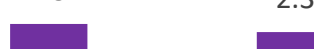

70-79
2.3

$80+$

Figure 1: Age distribution of participants

Table 2: Frequency distribution of Indication

\begin{tabular}{lll}
\hline INDICATION & $\mathrm{f}$ & $\%$ \\
\hline Itching & 3 & 1.0 \\
Pain & 74 & 24.0 \\
Lump & 119 & 38.6 \\
Nipple discharge & 19 & 6.2 \\
Nipple Retraction & 10 & 3.2 \\
Routine check & 73 & 23.7 \\
Breast swelling & 10 & 3.2 \\
Total & 308 & 100.0
\end{tabular}




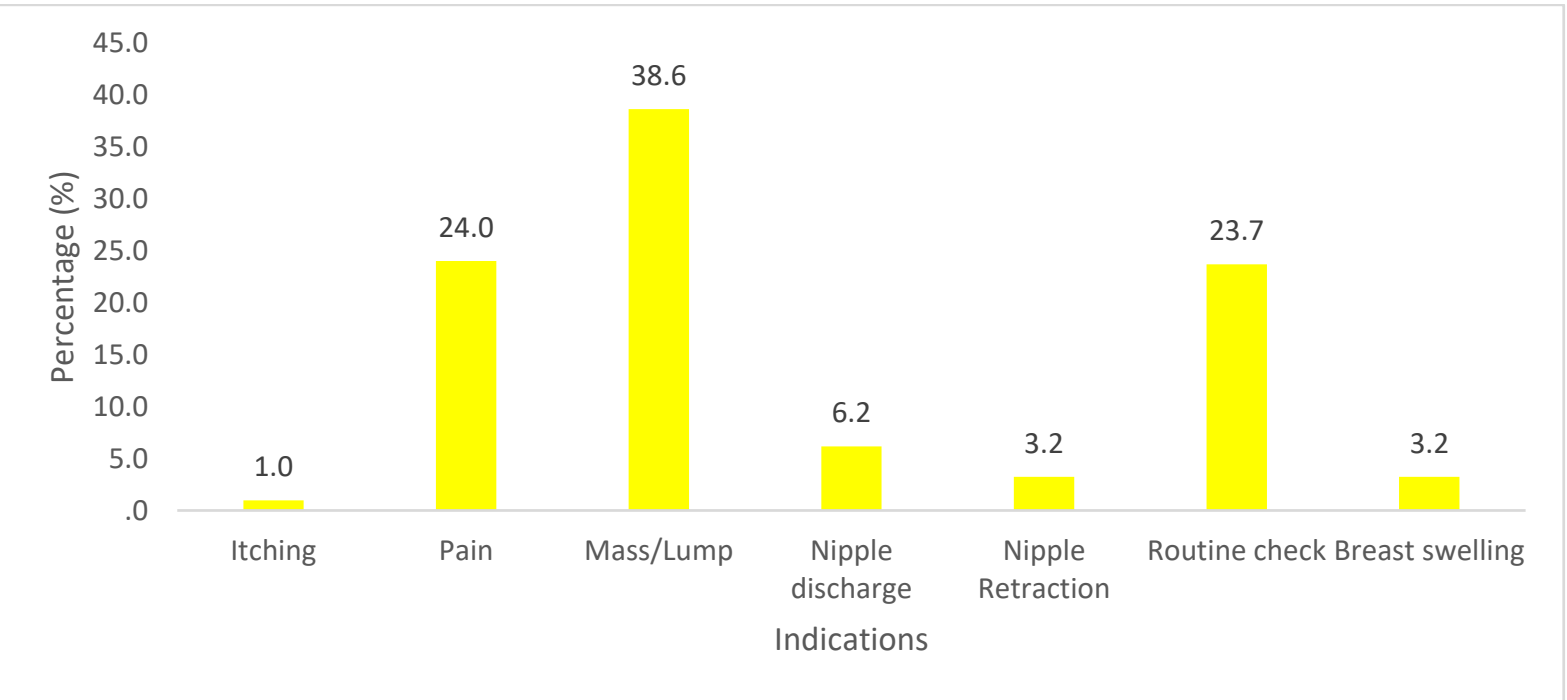

Figure 2: Frequency distribution of Indication

Table 3: Distribution of participants by BIRADS Scores

\begin{tabular}{lllllc}
\hline BIRADS & F & $\%$ & Mean \pm Std. & Min. & Max. \\
\hline 0 & 4 & 1.3 & $3.3 \pm 1.3$ & 1 & 6 \\
1 & 84 & 27.3 & & \\
2 & 124 & 40.3 & & \\
3 & 37 & 12.0 & & \\
4 & 29 & 9.4 & & \\
5 & 30 & 9.7 & & \\
Total & 308 & 100.0 & & \\
\hline
\end{tabular}

Table 4: Distribution of Age and BIRADS Scores

\begin{tabular}{|c|c|c|c|c|c|c|c|c|c|}
\hline \multirow{2}{*}{$\begin{array}{l}\text { Age } \\
\text { (Years) }\end{array}$} & \multicolumn{7}{|c|}{ BIRADS SCORES } & \multirow{2}{*}{$\begin{array}{l}\text { Chi- } \\
\text { square }\end{array}$} & \multirow{2}{*}{$\begin{array}{l}\mathrm{P}- \\
\text { value }\end{array}$} \\
\hline & 0 & 1 & 2 & 3 & 4 & 5 & Total & & \\
\hline $30-39$ & $0(0.0)$ & $9(10.7)$ & $14(11.3)$ & $4(10.8)$ & $4(13.8)$ & $2(6.7)$ & $33(10.7)$ & 37.614 & $0.023 *$ \\
\hline $40-49$ & $1(25.0)$ & $41(48.8)$ & $61(49.2)$ & $15(40.5)$ & $9(31.0)$ & $5(16.7)$ & $132(42.9)$ & & \\
\hline $50-59$ & $1(25.0)$ & $24(28.6)$ & $34(27.4)$ & $10(27.0)$ & $10(34.5)$ & $12(40.0)$ & $91(29.5)$ & & \\
\hline $60-69$ & $2(50.0)$ & $10(11.9)$ & $10(8.1)$ & $5(13.5)$ & $4(13.8)$ & $5(16.7)$ & $36(11.7)$ & & \\
\hline 70-79 & $0(0.0)$ & $0(0.0)$ & $2(1.6)$ & $3(8.1)$ & $1(3.4)$ & $3(10.0)$ & $9(2.9)$ & & \\
\hline $80+$ & $0(0.0)$ & $0(0.0)$ & $3(2.4)$ & $0(0.0)$ & $1(3.4)$ & $3(10.0)$ & $7(2.3)$ & & \\
\hline
\end{tabular}


International Journal of Scientific and Research Publications, Volume 7, Issue 8, August 2017 ISSN 2250-3153

Total

$4(100.0)$

84(100.0)

$124(100.0)$

$37(100.0)$

29(100.0)

$30(100.0)$

$308(100.0)$

* = Fisher's Exact Test 